\title{
Pain-Related Depression of the Mesolimbic Dopamine System in Rats: Expression, Blockade by Analgesics, and Role of Endogenous $\kappa$-opioids
}

\author{
Michael D Leitl', Sara Onvani' ${ }^{2}$, M Scott Bowers ${ }^{3}$, Kejun Cheng ${ }^{4}$, Kenner C Rice ${ }^{4}$, William A Carlezon Jr ${ }^{2}$, \\ Matthew L Banks' and S Stevens Negus*, I \\ 'Department of Pharmacology and Toxicology, Virginia Commonwealth University, Richmond, VA, USA; ${ }^{3}$ Behavioral Genetics Laboratory, McLean \\ Hospital, Harvard Medical School, Belmont, MA, USA; ${ }^{3}$ Department of Psychiatry, Virginia Commonwealth University, Richmond, VA, USA; \\ ${ }^{4}$ Chemical Biology Research Branch, National Institute on Drug Abuse and National Institute on Alcohol Abuse and Alcoholism, National \\ Institutes of Health, Bethesda, MD, USA
}

Pain is often associated with depression of behavior and mood, and relief of pain-related depression is a common goal of treatment. This study tested the hypothesis that pain-related behavioral depression is mediated by activation of endogenous $\kappa$-opioid systems and subsequent depression of mesolimbic dopamine release. Adult male Sprague-Dawley rats were implanted with electrodes targeting the medial forebrain bundle (for behavior studies of intracranial self-stimulation (ICSS)) or with cannulae for microdialysis measures of nucleus accumbens dopamine (NAc DA). Changes in ICSS and NAc DA were examined after treatment with a visceral noxious stimulus (intraperitoneal injection of dilute lactic acid) or an exogenous $\kappa$-agonist (U69593). Additional studies examined the sensitivity of acid and $U 69593$ effects to blockade by two analgesics (the nonsteroidal antiinflammatory drug ketoprofen and the $\mu$-opioid agonist morphine) or by the $\kappa$-antagonist norbinaltorphimine (norBNI). The effects of acid were also examined on mRNA expression for prodynorphin (PDYN) and א-opioid receptors (KORs) in mesocorticolimbic brain regions. Both acid and U69593 depressed ICSS and extracellular levels of NAc DA. Pain-related acid effects were blocked by ketoprofen and morphine but not by norBNI. The U69593 effects were blocked by norBNI but not by ketoprofen, and were only attenuated by morphine. Acid did not significantly alter PDYN or KOR in NAc, but it produced a delayed increase in PDYN in prefrontal cortex. These results support a key role for the mesolimbic DA system, but a more nuanced role for endogenous $\mathrm{\kappa}$-opioid systems, in mediating acute pain-related behavioral depression in rats. Neuropsychopharmacology (2014) 39, 6I4-624; do: I 0.1038/npp.2013.236; published online 2 October 2013

Keywords: dopamine; pain/analgesics; depression; nucleus accumbens; intracranial self-stimulation; dynorphin

\section{INTRODUCTION}

Pain is often associated with depression of behavior and mood, and relief from pain-related depression is a common goal of treatment with analgesic drugs (Bair et al, 2003; Cleeland and Ryan, 1994; Dharmshaktu et al, 2012). The mechanisms of pain-related depression are not well understood. In preclinical studies, injury, disease, or treatment with experimental noxious stimuli can produce an analgesic-reversible depression of behaviors that include feeding (Kwilasz and Negus, 2012; Stevenson et al, 2006), locomotion (Cobos et al, 2012; Stevenson et al, 2009), burrowing (Andrews et al, 2012), and positively reinforced

\footnotetext{
*Correspondence: Dr SS Negus, Department of Pharmacology and Toxicology, Virginia Commonwealth University, $410 \mathrm{~N}$ I2th Street, PO Box 9806/3, Richmond, VA 23298, USA, Tel: +I 804-828-3I58, Fax: + 804828 2117, E-mail: ssnegus@vcu.edu Received 17 June 2013; revised 20 August 2013; accepted 20 August 2013; accepted article preview online 6 September 2013
}

operant responding (Martin et al, 2004). For example, intracranial self-stimulation (ICSS) is an operant procedure in which subjects emit a learned response such as a lever press to earn pulses of electrical stimulation to brain reward areas (Carlezon and Chartoff, 2007; Olds and Milner, 1954). Tissue acidosis is a cardinal component of inflammation that contributes to nociception and pain (Bray et al, 2013; Deval et al, 2013), and intraperitoneal (i.p.) administration of exogenous acid functions as one type of physiologically relevant noxious visceral stimulus that depresses ICSS (Pereira Do Carmo et al, 2009; Negus, 2013). In addition, acid-induced depression of ICSS can be blocked by clinically effective analgesics including both $\mu$-opioid agonists such as morphine and nonsteroidal anti-inflammatory drugs (NSAIDs) such as ketoprofen (Kwilasz and Negus, 2012; Negus et al, 2010a, 2012; Pereira Do Carmo et al, 2009). Taken together, these observations suggest that acid-induced depression of ICSS may serve as a useful model for research on mechanisms of pain-related depression of behavior and brain reward systems. 
ICSS is mediated in part by activation of mesocorticolimbic dopamine (DA) neurons that originate in the ventral tegmental area and project to terminal regions that include nucleus accumbens (NAc) (Stellar and Stellar, 1985; Wise, 2008). The mesocorticolimbic DA system has a well-established role in mediating the rewarding effects of not only brain stimulation, but also natural reinforcers (eg, preferred foods) and of abused drugs (eg, stimulants and opioids) (Di Chiara and Imperato, 1988a; Wise, 2008). Depression of ICSS by noxious stimuli suggests that noxious stimuli may also depress signaling by mesolimbic DA neurons. This hypothesis is supported by other evidence that activity of DAergic neurons is negatively correlated with depressive dimensions of pain (Borsook et al, 2007; Jarcho et al, 2012; Wood, 2008). One goal of the present study was to test the hypothesis that i.p. acid-induced depression of ICSS would be associated with an analgesic-reversible depression of mesolimbic DA release as assessed by measures of extracellular NAc DA levels.

Pain-related depression of motivated behavior and of mesolimbic DA release could be mediated by a variety of different mechanisms, and elucidation of these mechanisms could suggest novel strategies for analgesic drug development. One possible mechanism is that noxious stimuli could activate endogenous dynorphin/ $/$-opioid receptor systems. Dynorphin is an endogenous opioid peptide generated from the precursor preprodynorphin, and it functions as a moderately selective agonist for the $\mathrm{K}$ subtype of opioid receptors (Chavkin et al, 1982). Ventral tegmental area DA neurons receive inputs from dynorphinergic neurons and express $\kappa$-receptors, and activation of these $\kappa$-receptors depresses neuronal activity and DA release (Knoll and Carlezon, 2010; Wee and Koob, 2010). For example, exogenous $\kappa$-agonists such as salvinorin A and U69593 decrease both mesolimbic DA release and behaviors such as ICSS that depend on mesolimbic DA release (Carlezon et al, 2006; Di Chiara and Imperato, 1988b; Negus et al, 2012; Todtenkopf et al, 2004; Zhang et al, 2005). Moreover, recent studies suggest that some nonnoxious stressors (eg, forced swim in rats) activate dynorphin/א-systems to produce depressive-like effects that can be blocked by $\kappa$-opioid receptor antagonists (Bruchas et al, 2010; Chartoff et al, 2009; McLaughlin et al, 2003). These findings have been interpreted to suggest that $\kappa$-antagonists represent a novel class of candidate antidepressants that could block depressive-like effects associated with stress-induced dynorphin release. Accordingly, a secondary goal of the present study was to assess the degree to which acid-induced depression of ICSS and NAc DA release might be (1) mediated by activation of endogenous dynorphin;/ $/$-systems, and (2) blocked by a $\kappa$-antagonist.

\section{MATERIALS AND METHODS}

\section{Subjects}

Male Sprague-Dawley rats (Harlan, Frederick, MD) with initial weights of 285 to $400 \mathrm{~g}$ at the time of surgery were used for studies of ICSS and microdialysis. Rats were individually housed and maintained on a 12-h light/dark cycle with lights on from $0600 \mathrm{~h}$ to $1800 \mathrm{~h}$. Food and water were continuously available in the home cage. Animal maintenance and research were in compliance with National Research Council (2011) Guide for the Care and Use of Laboratory Animals (National Academies Press, Washington, DC). In addition, animal-use protocols were approved by the Virginia Commonwealth University institutional animal care and use committee.

\section{Assay of Microdialysis}

Surgery. A total of 30 rats were anesthetized with $2.5 \%$ isoflurane in oxygen until unresponsive to toe-pinch and secured in a sterotaxic apparatus (Kopf Instruments, Tujunga, CA). Guide cannulae ( $8 \mathrm{~mm}$ long, $0.5 \mathrm{~mm}$ outer diameter; CXG-8, Eicom, San Diego, CA) were implanted bilaterally and terminated $1 \mathrm{~mm}$ above the NAc $(1.5 \mathrm{~mm}$ anterior to bregma, $1.8 \mathrm{~mm}$ lateral to midsaggital line, and $6.0 \mathrm{~mm}$ ventral to dura). A dummy cannula (CXD8 , Eicom) was inserted into each guide cannula to maintain patency. The guide cannulae were secured to the skull with screws and dental acrylic. Animals were allowed to recover for at least 4 days before initiation of microdialysis testing.

Procedure. On a test day, rats were briefly anesthetized with $2 \%$ isoflurane in oxygen, one dummy cannula was removed, and a microdialysis probe (CX-I-8-2, Eicom) with a 2-mm regenerated cellulose membrane $(50 \mathrm{KDa}$ molecular weight cutoff) was inserted through the guide cannula and into the NAc. The probe was connected to a two-channel liquid swivel (TCS2-23, Eicom), and the rat was placed in a clear plexiglass chamber $(30 \mathrm{~cm} \times 30 \mathrm{~cm} \times 30 \mathrm{~cm})$. Probes were perfused with a nonbuffered artificial cerebrospinal fluid solution $\left(147 \mathrm{~mm} \mathrm{NaCl}, 2.8 \mathrm{~mm} \mathrm{KCl}, 1.2 \mathrm{~mm} \mathrm{CaCl}_{2}\right.$, $1.2 \mathrm{mM} \mathrm{MgCl}_{2}$ ) at a rate of $1 \mu \mathrm{l} / \mathrm{min}$. Following an equilibration period of at least $60 \mathrm{~min}$, dialysate samples were collected into a $50 \mu \mathrm{l}$ injector loop at 6 -min intervals using an EAS-20s online autoinjector (Eicom) and immediately analyzed for DA concentrations by high-pressure liquid chromatography coupled to electrochemical detection (HTEC-500, Eicom). Preliminary experiments conducted by probe immersion into a known standard concentration of DA indicated a lag time of $24 \mathrm{~min}$ for dialysate to traverse the tubing from the probe to the electrochemical detector at the $1 \mu \mathrm{l} / \mathrm{min}$ flow rate (data not shown). The mobile phase consisted of $2 \%$ methanol (EMD, Gibbstown, NJ), $100 \mathrm{~mm}$ phosphate buffer (Sigma Chemicals, St Louis, MO), $500 \mathrm{mg} / \mathrm{l}$ 1-Decane sodium sulfonate (TCI America, Montgomeryville, PA), and $50 \mathrm{mg} / \mathrm{l} \mathrm{EDTA-}$ 2NA (Dojindo Laboratories, Kumamoto, Japan). DA was separated using a PP-ODS II reverse phase C18-column and detected using a graphite work electrode and an $\mathrm{Ag} v s \mathrm{AgCl}$ reference electrode with an applied potential of $+450 \mathrm{mV}$. DA was identified according to the retention time of the standard, and concentrations were quantified by comparison with peak heights of the standard concentration curve (0.01-100 pg per $10 \mu \mathrm{l})$ determined before each microdialysis experiment to ensure accuracy of standard retention times. Resolution was sufficient to detect DA levels as low as $0.1 \mathrm{pg}$. DA levels were considered to have stabilized after collection of 10 consecutive baseline samples with $<10 \%$ 
variability around the running mean. Testing was conducted using drugs, doses, and pretreatment times based on previous behavioral studies from our laboratory (see below; (Altarifi and Negus, 2011; Negus et al, 2010b; Negus et al, 2012)). Specifically, ketoprofen $(3.2 \mathrm{mg} / \mathrm{kg})$, morphine $(3.2 \mathrm{mg} / \mathrm{kg})$, or vehicle was administered subcutaneously 30 min before intraperitoneal administration of dilute lactic acid $(5.6 \%$ in $1 \mathrm{ml} / \mathrm{kg}), \mathrm{U} 69593(0.56 \mathrm{mg} / \mathrm{kg})$, or vehicle, and DA levels were recorded at 6-min intervals for $120 \mathrm{~min}$. A higher ketoprofen dose $(3.2 \mathrm{mg} / \mathrm{kg})$ was used here than previously $(1.0 \mathrm{mg} / \mathrm{kg}$; Negus et al, 2012) because of the higher intensity noxious stimulus $(5.6 \%$ vs $1.8 \%$ lactic acid, respectively). The dose of U69593 was selected based on preliminary studies to identify a dose that produced depression of mesolimbic DA to a degree comparable to that produced by lactic acid. Following the experimental session, each rat (regardless of treatment) was administered $1.0 \mathrm{mg} / \mathrm{kg}$ d-amphetamine subcutaneously as a positive control to assess sensitivity of the preparation to a DA releaser (Baumann et al, 1994; Di Chiara and Imperato, 1988a). Rats were tested twice, once for each cannula, and treatments were counterbalanced. At the end of the experiments, rats were euthanized with $\mathrm{CO}_{2}$, and the brains were removed and stored in 10\% formalin. Brain tissue was blocked around the anatomic site of the guide cannula, and sections $(100 \mu \mathrm{m}$ thick) were made by vibratome through the area. The brain sections were then stained with cresyl violet. Anatomical probe placement was verified by gross visual and microscopic examination.

A 4-day experimental design was used in experiments with the $\kappa$-opioid antagonist norbinaltorphimine (norBNI) to accommodate its slow onset and long duration of action (Bruchas et al, 2007; Endoh et al, 1992), and two groups of rats were used to examine the effects of norBNI pretreat- ment on the effects of i.p. acid and U69593, respectively. In each group, norBNI $(32 \mathrm{mg} / \mathrm{kg}$ ) was administered on day 1 , and microdialysis test sessions were conducted on days 2 and 4 . In one group of rats, the effects of vehicle and dilute acid $(5.6 \%$ in $1 \mathrm{ml} / \mathrm{kg})$, were examined on days 2 and 4 , whereas in the second group, the effects of vehicle and U69593 $(0.56 \mathrm{mg} / \mathrm{kg})$ were examined on days 2 and 4 . In each group, the order of testing was counterbalanced across rats. Microdialysis sampling sessions identical to those described above were conducted on test days. The effects of vehicle, lactic acid, or U69593 after norBNI pretreatment were compared with the effects of vehicle, lactic acid, or U69593 administered alone.

Histology. After microdialysis experiments, rats were euthanized by $\mathrm{CO}_{2}$, and the brains were removed and placed in $10 \%$ formalin for at least 1 week. Tissue was blocked around the anatomic site of the guide cannula, and sections $(100 \mu \mathrm{m}$ thick) were made by vibratome through the area. The brain sections were then stained with cresyl violet. Anatomical placement was verified by gross visual and microscopic examination.

Data analysis. The primary dependent variable was the concentration of DA in each dialysate fraction. DA concentrations in each fraction for each rat were expressed as percent of the average of the 10 mean baseline concentrations before drug or vehicle administration. Two-way repeated measures ANOVA with treatment and time were used as the two main factors in Figure 1a. This experiment indicated that maximal decreases in DA levels were observed from 60 to $90 \mathrm{~min}$ after injection of acid, and a similar time course was observed for depression of

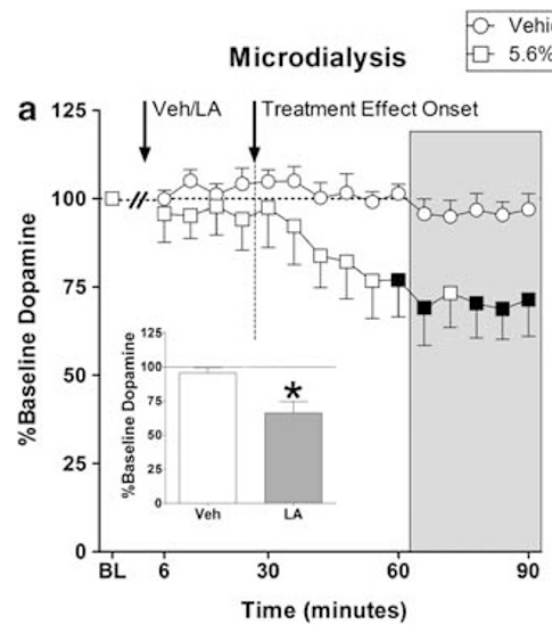

ICSS

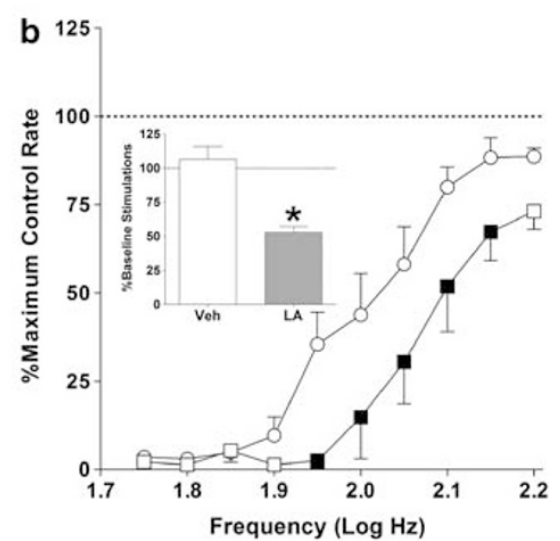

Figure I Pain-related depression of (a) nucleus accumbens dopamine levels and of (b) intracranial self-stimulation (ICSS) by i.p. injection of dilute lactic acid (5.6\% in a volume of $1 \mathrm{ml} / \mathrm{kg}$ ). (a) The abscissa shows time after injection of 5.6\% lactic acid or its vehicle and the ordinate shows \% baseline dopamine levels. The vertical line at $24 \mathrm{~min}$ indicates the lag time required for dialysate to traverse tubing between the dialysis probe and the electrochemical detector. The shaded area from 60 to 90 min shows asymptotic depression that was averaged for subsequent analyses. (b) The abscissa shows frequency of electrical brain stimulation $(\log \mathrm{Hz})$ and the ordinate shows ICSS rate expressed as percent maximum control rate (\%MCR). Data were collected from 10 to 30 min after vehicle or acid injection, which corresponds to the time of declining dopamine levels in (a). In both panels, filled points indicate statistical significance of acid vs vehicle effects using two-way repeated measures ANOVA with Student-Newman-Keuls post hoc $(p<0.05)$. Insets show average dopamine levels during the period indicated by the shaded region (a, expressed as \% baseline dopamine levels) or average ICSS rates across all frequencies (b, expressed as \% baseline stimulations across all frequencies). Asterisks (*) indicate a significant effect of acid as indicated by $t$-test $(p<0.05)$. All data show mean $\pm S E M$ from 5 to 7 rats. 
mesolimbic DA by U69593. Accordingly, mean DA levels observed from 60 to $90 \mathrm{~min}$ after acid/U69593/vehicle injection were used for subsequent analyses. Treatment effects on mean DA levels during this time window were analyzed by one-way ANOVA. Significant ANOVAs were followed by the Student-Newman-Keuls post hoc test, and significance was set a priori at the $95 \%$ level of confidence $(p<0.05)$.

\section{Assay of ICSS}

Surgery. In all, 48 rats were anesthetized and secured in a sterotaxic apparatus as described above. The cathode of a stainless steel electrode $(0.25 \mathrm{~mm}$ diameter, insulated except at flattened tip) was inserted into the medial forebrain bundle at the level of the lateral hypothalamus $(2.8 \mathrm{~mm}$ posterior to bregma, $1.7 \mathrm{~mm}$ lateral to midsaggital line, and $8.8 \mathrm{~mm}$ ventral to skull). Three screws were placed in the skull, and the anode $(0.125 \mathrm{~mm}$ diameter, uninsulated) was wrapped around one of the screws to act as a ground. The electrode was secured to the skull with dental acrylic. Animals were allowed to recover for at least 7 days before beginning ICSS training.

Apparatus. Experiments were conducted in sound-attenuating boxes that contained modular acrylic test chambers $\left(29.2 \times 30.5 \times 24.1 \mathrm{~cm}^{3}\right)$ equipped with a response lever $(4.5 \mathrm{~cm}$ wide, extended $2.0 \mathrm{~cm}$ through the center of one wall, and $3 \mathrm{~cm}$ off the floor), stimulus lights (three lights colored red, yellow, and green, positioned $7.6 \mathrm{~cm}$ directly above the response lever), a 2-W white house light, and an ICSS stimulator (MED Associates, St Albans, VT). Electrodes were connected to the stimulator via a swivel connector (model SL2C; Plastics One). The stimulator was controlled by computer software that also controlled all of the programming parameters and data collection (MED Associates).

Behavioral procedure. After initial shaping of lever-press responding, rats were trained under a fixed-ratio 1 schedule of brain stimulation by using procedures similar to those described previously (Negus et al, 2010a, b). During initial training sessions lasting 30 to $60 \mathrm{~min}$, the white house light was illuminated, and responding produced electrical stimulation under a fixed-ratio 1 schedule of reinforcement. Under this schedule, each lever press resulted in the delivery of a 0.5 -s train of square-wave cathodal pulses (0.1-ms pulse duration) and illumination for $0.5 \mathrm{~s}$ of the colored stimulus lights over the lever. Responses during the 0.5-s stimulation period did not earn additional stimulation. Initially, the frequency of stimulation was held constant at $126 \mathrm{~Hz}$, and the stimulation intensity for each rat was adjusted gradually to the lowest value that would sustain a high rate of ICSS ( $\geqslant 30$ stimulations/min). Frequency manipulations were then introduced, and the terminal schedule consisted of sequential 10-min components. During each component, a descending series of 10 current frequencies was presented, with a 60-s trial at each frequency. The frequency range extended from 158 to $56 \mathrm{~Hz}$ in $0.05-\log$ increments. Each frequency trial began with a 10-s timeout, during which the house light was off and responding had no scheduled consequences. During the last $5 \mathrm{~s}$ of this timeout, five noncontingent stimulations were delivered once per second at the frequency available during that trial, and the lever lights were illuminated during each stimulation. This noncontingent stimulation was then followed by a 50-s 'response' period, during which the house light was illuminated, and responding produced electrical stimulation under the schedule described above. Training continued with presentation of three sequential components per day, and intensity was again adjusted as necessary until rats reliably responded for at least three and no more than six trials of all components for at least two consecutive days. Testing was conducted using drugs, doses, and pretreatment times identical to those used in microdialysis experiments, and as noted above, these parameters were based on previous studies from our laboratory (Altarifi and Negus, 2011; Negus et al, 2010b, 2012). ICSS test sessions consisted of seven sequential components. The first component of each test session was considered to be an acclimation component, and data from this component were discarded. Data from the second and third 'baseline' components were used to calculate baseline parameters of frequency-rate curves for that session (see Data Analysis). After these baseline components, ketoprofen $(3.2 \mathrm{mg} / \mathrm{kg})$, morphine $(3.2 \mathrm{mg} / \mathrm{kg})$, or vehicle was administered subcutaneously $30 \mathrm{~min}$ before i.p. administration of dilute lactic acid $(5.6 \%$ in $1 \mathrm{ml} / \mathrm{kg}), \mathrm{U} 69593$ $(0.56 \mathrm{mg} / \mathrm{kg})$, or vehicle. Two sequential pairs of 10 -min test components were then conducted 10-30 min and 70-90 min after the second injection. Testing was conducted twice per week (usually Tuesday and Friday), and the order of treatments for a group of rats was arranged according to a within-subject, counterbalanced design. Training sessions were conducted on other weekdays.

As in the microdialysis studies, a 4-day experimental design was used in experiments with norBNI, and two groups of rats were used to examine the effects of norBNI pretreatment on the effects of intraperitoneal acid and U69593, respectively. In each group, norBNI $(32 \mathrm{mg} / \mathrm{kg}$ ) was administered on day 1 , and ICSS test sessions were conducted on days 2 and 4 at 24 and $72 \mathrm{~h}$ after norBNI administration. In one group of rats, the effects of vehicle and dilute acid $(5.6 \%$ in $1 \mathrm{ml} / \mathrm{kg})$ were examined on days 2 and 4 , whereas in the second group, the effects of vehicle and U69593 $(0.56 \mathrm{mg} / \mathrm{kg})$ were examined on days 2 and 4 . In each group, the order of testing was counterbalanced across rats. ICSS test sessions identical to those described above were conducted on test days.

Data analysis. The primary dependent variable was the reinforcement rate in stimulations/trial during each frequency trial. To normalize these data, raw reinforcement rates from each trial in each rat were converted to percentage of maximum control rate (\%MCR), with the maximum control rate defined as the mean of the maximal rates observed during any frequency trial of the second and third baseline components for that session. Thus, \%MCR values for each trial were calculated as (response rate during a frequency trial $\div$ maximum control rate) $\times 100$. For each test session, data from the second and third components were averaged to yield a baseline frequency-rate curve, and 
data from each pair of test components were averaged to yield test frequency-rate curves for the 10-30 min and 70-90 min time points. Baseline and test curves were then averaged across rats to yield mean baseline and test curves for each manipulation. For statistical analysis, results were compared by two-way, within-subject ANOVA, with treatment and ICSS frequency as the two factors. A significant ANOVA was followed by the Student-Newman-Keuls post hoc test, and the criterion for significance was set a priori at $p<0.05$.

As an additional summary measure of ICSS performance, the total number of stimulations per component obtained across all frequencies was determined, and the average number of stimulations per test component was expressed as a percentage of the average number of stimulations per baseline component during each session. These values were then averaged across rats in each experimental condition and compared by one-way ANOVA. A significant ANOVA was followed by the Student-Newman-Keuls post $h o c$ test, and the criterion for significance was set a priori at $p<0.05$.

\section{Quantitative Real-Time Reverse Transcriptase PCR}

Procedure. A total of 36 rats were used for quantitative real-time reverse transcriptase PCR (qRT-PCR) studies designed to assess the effects of acid noxious stimulus on endogenous prodynorphin (PDYN) and $\kappa$-opioid receptor (KOR) mRNA. Rats were treated with i.p. saline vehicle or $5.6 \%$ lactic acid in a volume of $1 \mathrm{mg} / \mathrm{kg}$ and then killed by rapid decapitation after $1.5 \mathrm{~h}, 24 \mathrm{~h}$, or 4 days $(N=6$ per treatment and time point). Brains were immediately extracted, rapidly frozen in $-80^{\circ} \mathrm{C}$ isopentane, and stored at $-80^{\circ} \mathrm{C}$ until analysis. Tissue punches were collected by sectioning frozen brains on a cryostat at $-20{ }^{\circ} \mathrm{C}$ until the areas of interest were exposed. Bilateral punches of tissues from prefrontal cortex (PFC), NAc shell (NAcSh), NAc core (NAcC), caudate/putamen $(\mathrm{CPu})$, and ventral tegmental area (VTA) were then collected and placed in Eppendorf tubes on dry ice. Total RNA was purified using PureLink RNA Mini Kit (Ambion). RNA quantity was measured (Nanodrop 2000, Thermo Scientific), and cDNA was synthesized from $500 \mathrm{ng}$ of total RNA by using the iScript cDNA Synthesis Kit (Bio-Rad) and a ThermoHybrid iCycler (Thermo Scientific). The qPCR reactions were performed using the iQ SybrGreen Supermix (Bio-Rad) and the following primer pairs: KOR (5'-CTCCCAGTGCTTGCCTACTC- $3^{\prime}$, and $5^{\prime}$-AGATGTTGGTTGCGGTCTTC- $3^{\prime}$ ), PDYN (5'-ACTGCCTGTCCTTGTGTTCC- ${ }^{\prime}$ and $5^{\prime}$-CCAAAGCAAC CTCATTCTCC- $3^{\prime}$ ), $\beta$-actin (NBA; $5^{\prime}$-AGGGAAATCGTGC GTGACAT- $3^{\prime}$ and $5^{\prime}$-AAGGAAGGCTGGAAG AGAGC-3'), and Calnexin (CNX; 5'-GCTCTGGTCCATGACATCCG- $3^{\prime}$ and $5^{\prime}$-CAGCATCTGCCCCACTACAC-3'). Primer specificity was confirmed by melt-curve analysis and polyacrylamide gel electrophoresis. The PCR reaction mix consisted of: $10 \mu \mathrm{l}$ SybrGreen Supermix; $2 \mu \mathrm{l}$ RNase/DNase-free water; $2 \mu \mathrm{l}(3 \mu \mathrm{M})$ of each forward and reverse primers; and $4 \mu \mathrm{l}$ (200 ng) cDNA template. Amplification was performed on a MyiQ Single Color Real-Time PCR Detection System (Bio-Rad) under the following protocol: $95^{\circ} \mathrm{C}$ for $5 \mathrm{~min} ; 40$ cycles at $94{ }^{\circ} \mathrm{C}$ for $15 \mathrm{~s}, 60^{\circ} \mathrm{C}$ for $15 \mathrm{~s}$, and $70^{\circ} \mathrm{C}$ for $20 \mathrm{~s}$. Read temperature for data collection was set between $81{ }^{\circ} \mathrm{C}$ and $86^{\circ} \mathrm{C}$ for $15 \mathrm{~s}$ depending on the primer pair. A master cDNA mix was generated by mixing $10 \mu \mathrm{l}$ of cDNA from all samples and used to produce a standard dilution curve on each plate. This was accomplished by serially diluting the master mix $(1,0.25,0.0625$, and 0.0156$)$ and assigning to the undiluted sample an arbitrary concentration of 1 in the MyiQ Optical System Software (Bio-Rad). Two samples, each of which lacked either the cDNA template or reverse transcriptase enzyme, were run on every plate to control for reagent contamination and genomic DNA contamination, respectively. All samples were run in triplicate.

Data analysis. To normalize data, $\kappa$-opioid receptor and prodynorphin values were divided by the average values of the two internal controls ( $\beta$-actin and Calnexin). Values are reported as percent vehicle controls calculated as (normalized vehicle and experimental means/normalized vehicle group mean for the corresponding time point) $\times 100$. Data for PDYN and KOR $\mathrm{mRNA}$ in each region were analyzed using two-way ANOVA with treatment and time as the two factors, followed by the Bonferroni post hoc test. The criterion for significance was set at $p<0.01$ to correct for multiple comparisons across the five different regions examined.

\section{Drugs}

Lactic acid (Spectrum Chemical, Gardena, CA), U69593 (National Institute on Drug Abuse Drug Supply Program, Bethesda, MD), ketoprofen propionate (Spectrum Chemical), morphine sulfate (National Institute on Drug Abuse Drug Supply Program), d-amphetamine hemisulfate (Sigma Aldrich, St Louis, MO), and norBNI $2 \mathrm{HCl}$ (synthesized by $\mathrm{K}$ Cheng and K Rice, National Institutes of Health, Bethesda, MD) were dissolved and/or diluted in sterile water. Lactic acid and U69593 were administered i.p. in a volume of $1 \mathrm{ml} / \mathrm{kg}$. Ketoprofen, morphine, and d-amphetamine were administered subcutaneously in a volume of $1 \mathrm{ml} / \mathrm{kg}$. Norbinaltorphimine was administered i.p. in a volume of $1.5 \mathrm{ml} / \mathrm{kg}$. All doses were calculated using the salt forms of each drug as listed above.

\section{RESULTS}

Effects of Intraperitoneal Lactic Acid on NAc DA Levels and ICSS

Over the course of the study, baseline extracellular DA levels in NAc were $1.0 \pm 0.1 \mathrm{pg}$ per $5 \mu \mathrm{l}$. Supplementary Figure 1 shows histologically confirmed placements of microdialysis probes and the stability of baseline DA measurements over time. Figure 1a shows that i.p. vehicle injection had no effect on NAC DA, whereas i.p. injection of $5.6 \%$ lactic acid produced a time-dependent decrease in DA. DA levels did not change for the first four samples (0-24 min) after acid injection because of the lag time for dialysate to travel from the probe to the electrochemical detector. Beginning at the time of treatment effect onset at the detector, DA levels decreased for the next seven samples (24-66 min after injection of vehicle or lactic acid, 0-42 min after treatment effect onset at the detector), and reached a nadir for the last 
five samples (60-90 min after injection, 36-66 min after treatment effect onset at the detector).

Treatment with the noxious lactic acid stimulus also depressed ICSS. Over the course of the study, the mean \pm SEM maximum control rate of ICSS was $59.8 \pm 1.5$ stimulations/trial, and the mean total number of stimulations/ component delivered across all frequencies was $291 \pm 13$. Figure $1 \mathrm{~b}$ shows that, relative to vehicle treatment, $5.6 \%$ lactic acid (i.p.) depressed ICSS from 10 to $30 \mathrm{~min}$ after acid injection, producing a rightward shift in the ICSS frequency-rate curve and significant decreases in ICSS at frequencies of $1.95-2.15 \log \mathrm{Hz}$. ICSS was no longer significantly depressed 70-90 min after acid injection (data not shown). The relative time courses of these effects will be addressed in the Discussion section, but briefly, these data suggest that behavioral depression was associated with declining DA levels rather than with the absolute DA levels.

Effects of Ketoprofen, Morphine, and NorBNI on Lactic Acid- or U69593-Induced Depression of NAc DA Levels and ICSS

Figure 2a shows that both the NSAID ketoprofen $(3.2 \mathrm{mg} / \mathrm{kg}$, s.c.) and the $\mu$-opioid analgesic morphine $(3.2 \mathrm{mg} / \mathrm{kg}$, s.c.) blocked acid-induced depression of NAc DA at doses that did not significantly alter DA levels in the absence of the noxious stimulus. Figure $2 \mathrm{~b}$ shows that the same doses of ketoprofen and morphine also blocked acid-induced depression of ICSS at doses that did not significantly alter ICSS in the absence of the noxious stimulus.

Figure 3 shows that the $\kappa$-agonist U69593 $(0.56 \mathrm{mg} / \mathrm{kg})$ decreased both NAc DA levels and ICSS (Supplementary Figure 2 shows a more detailed display of these effects homologous to Figure 1), and both effects of U69593 were completely antagonized by the $\kappa$-antagonist norBNI. Ketoprofen failed to block U69593-induced depression of either NAc DA levels or ICSS. Morphine significantly attenuated U69593-induced depression of NAc DA levels, but did not alter U69593-induced depression of ICSS. Figure 4 shows that a dose of norBNI that fully blocked U69593-induced depression of NAc DA and ICSS did not alter lactic acid-induced depression of either NAc DA or ICSS.

\section{Effects of Intraperitoneal Lactic Acid on Transcript Levels for Prodynorphin and the $\kappa$-Receptor}

Figure 5 shows that acid injection significantly increased PDYN expression in PFC at 4 days after acid injection. No significant changes in PDYN expression were observed in the PFC at earlier times, and no significant changes in PDYN expression were observed in $\mathrm{NAcC}, \mathrm{NAcSh}, \mathrm{CPu}$, or VTA at any time. No significant changes in KOR expression levels were observed in any region at any time.

\section{DISCUSSION}

In agreement with previous studies, i.p. administration of dilute lactic acid served as a physiologically relevant noxious stimulus to produce an analgesic-reversible depression of ICSS, an operant procedure in which lever-press responding is maintained by electrical stimulation of a key brain reward area. The present study extended this finding in three ways. First, the acid noxious stimulus also depressed extracellular levels of the neurotransmitter DA in the NAc. The magnitude and valence of this effect was similar to the depression of DA release produced by some other dysphoric/aversive stimuli, such as $\kappa$-agonists, and opposite to the stimulation of DA release produced by drugs of abuse and other rewarding/reinforcing stimuli. Accordingly, these data are consistent with the conclusion that depression of mesolimbic DA release may contribute to negative affective dimensions of pain. Second, acid-induced depression of NAc DA release was blocked by both NSAID and opioid analgesics. The sensitivity of acid effects to analgesic drugs provides further support for the potential relationship of these effects to affective dimensions of pain. Third, the acid noxious stimulus perturbed mesocorticolimbic PDYN expression, but the results of this study did not support a critical role for the dynorphin/ $\kappa$-opioid receptor system in mediating pain-related depression of
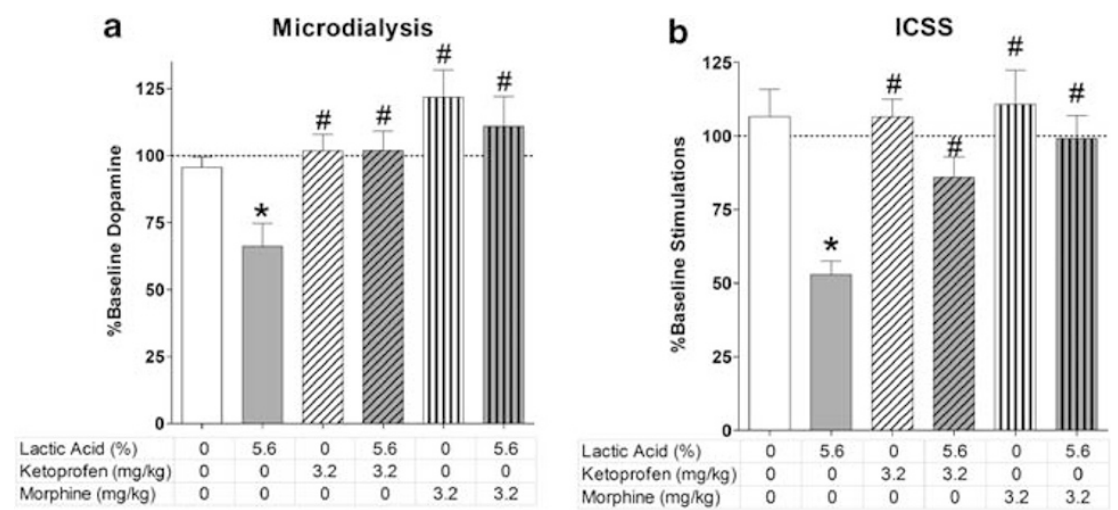

Figure 2 Effects of the analgesics ketoprofen and morphine on acid-induced depression of (a) nucleus accumbens dopamine levels and of (b) intracranial self-stimulation (ICSS). (a) The abscissa shows treatment conditions and the ordinate shows \% baseline dopamine levels from 60 to 90 min after administration. (b) The abscissa shows treatment conditions and the ordinate shows \% baseline stimulations from 10 to 30 min after administration. Asterisks (*) indicate significantly different from vehicle conditions, and the symbol (\#) indicates significantly different from acid alone as determined by one-way ANOVA followed by the Student-Newman-Keuls post hoc test $(p<0.05)$. All data show mean \pm SEM from 5 to 7 rats. 

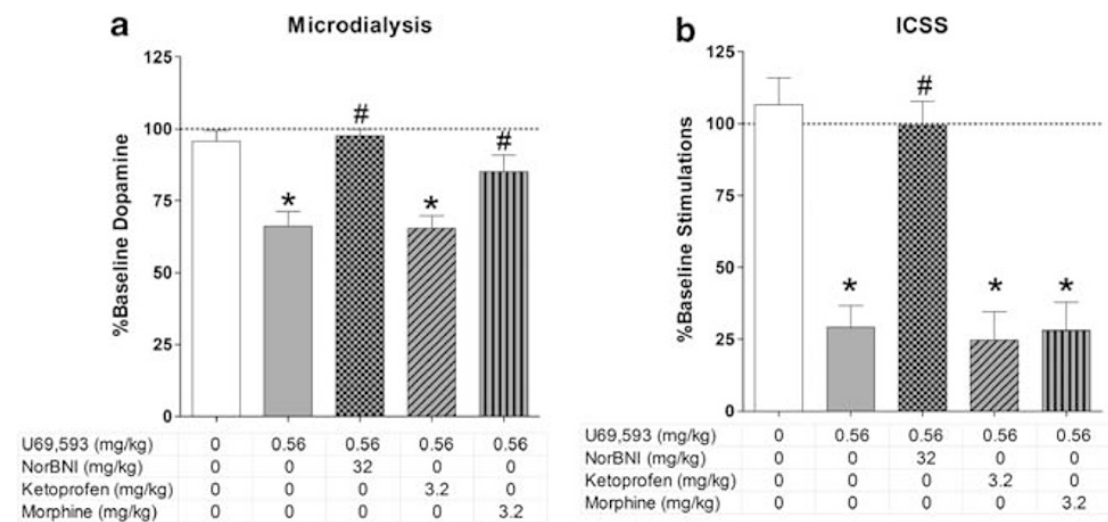

Figure 3 Effects of the $\kappa$-antagonist norBNI and of the analgesics ketoprofen and morphine on U69593-induced depression of (a) nucleus accumbens dopamine levels and of (b) intracranial self-stimulation (ICSS). (a) The abscissa shows treatment conditions and the ordinate shows \% baseline dopamine levels from 60 to 90 min after administration. (b) The abscissa shows treatment conditions and the ordinate shows \% baseline stimulations from 10 to 30 min after administration. Asterisks (*) indicate significantly different from vehicle conditions, and the symbol (\#) indicates significantly different from U69593 alone as determined by one-way ANOVA followed by the Student-Newman-Keuls post hoc test $(p<0.05)$. All data show mean \pm SEM from 5 to 7 rats.
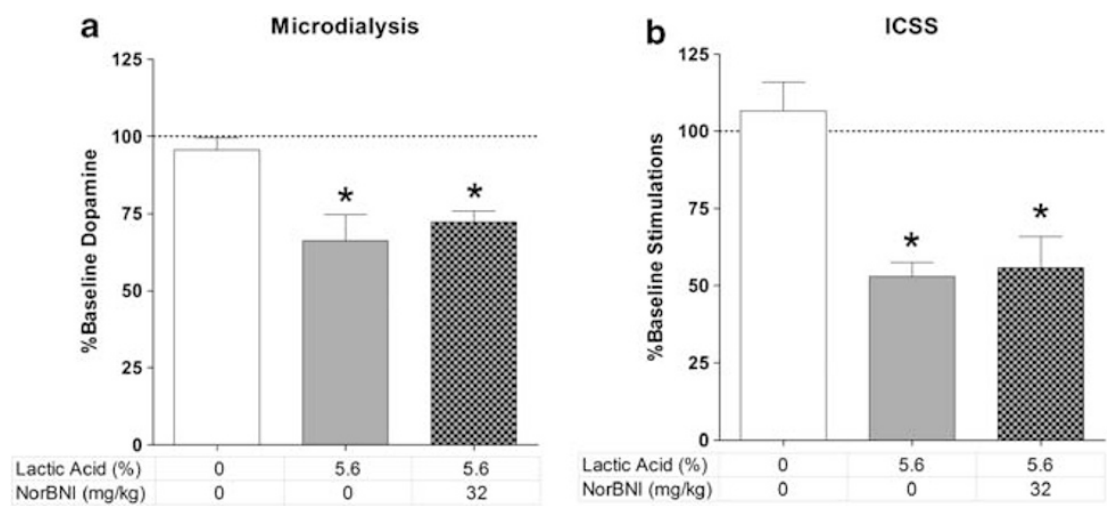

Figure 4 Effects of the $\kappa$-antagonist norBNI on acid-induced depression of (a) nucleus accumbens dopamine levels and of (b) intracranial self-stimulation (ICSS). (a) The abscissa shows treatment conditions and the ordinate shows \% baseline dopamine levels from 60 to 90 min after administration. (b) The abscissa shows treatment conditions and the ordinate shows \% baseline stimulations from 10 to 30 min after administration. Asterisks (*) indicate significantly different from vehicle conditions as determined by one-way ANOVA followed by the Student-Newman-Keuls post hoc test ( $p<0.05)$. All data show mean \pm SEM from 5 to 7 rats.

ICSS and NAc DA. In particular, the $\kappa$-antagonist norBNI failed to produce analgesic-like effects.

\section{Pain-Related Depression of Behavior}

In agreement with previous studies (Kwilasz and Negus, 2012; Negus et al, 2010b, 2012; Pereira Do Carmo et al, 2009), i.p.administration of dilute lactic acid served as a noxious stimulus to produce an analgesic-reversible depression of ICSS. This study extended previous findings by using a higher intensity noxious stimulus (5.6\% vs $1.8 \%$ lactic acid, see below), and despite use of this higher intensity stimulus, both ketoprofen and morphine retained efficacy to block acid-induced depression of ICSS. These results also agree with previous studies showing painrelated and analgesic-reversible depression of other behaviors including feeding (Kwilasz and Negus, 2012; Stevenson et al, 2006), locomotion (Cobos et al, 2012; Stevenson et al, 2009), burrowing (Andrews et al, 2012), and positively reinforced operant responding (Martin et al, 2004).

\section{Pain-Related Depression of Mesolimbic DA Release}

In the present study, acid-induced depression of ICSS was accompanied by acid-induced depression of NAc DA levels. In this regard, the effects of acid noxious stimulus were similar to the effects of $\mathrm{K}$-agonist U69593 and, as will be discussed further below, that similarity provided one rationale for the hypothesis that acid effects were mediated by activation of the endogenous dynorphin/ $/$-opioid receptor system. However, before addressing that issue, it is relevant first to consider the relationship between the time course and potency of neurochemical and behavioral effects produced by i.p. acid and U69593. First, regarding time course, both acid and U69593 produced an initial period of declining DA levels followed by a later period of relatively sustained but reduced DA levels. The time course of ICSS depression corresponded more closely to the time course of declining rather than absolute DA levels, although significant depression of behavior was observed before significant depression of NAc DA levels. A similar temporal relationship has been reported previously for the neurochemical and behavioral effects of the $\mathrm{K}$-agonist salvinorin $\mathrm{A}$ 

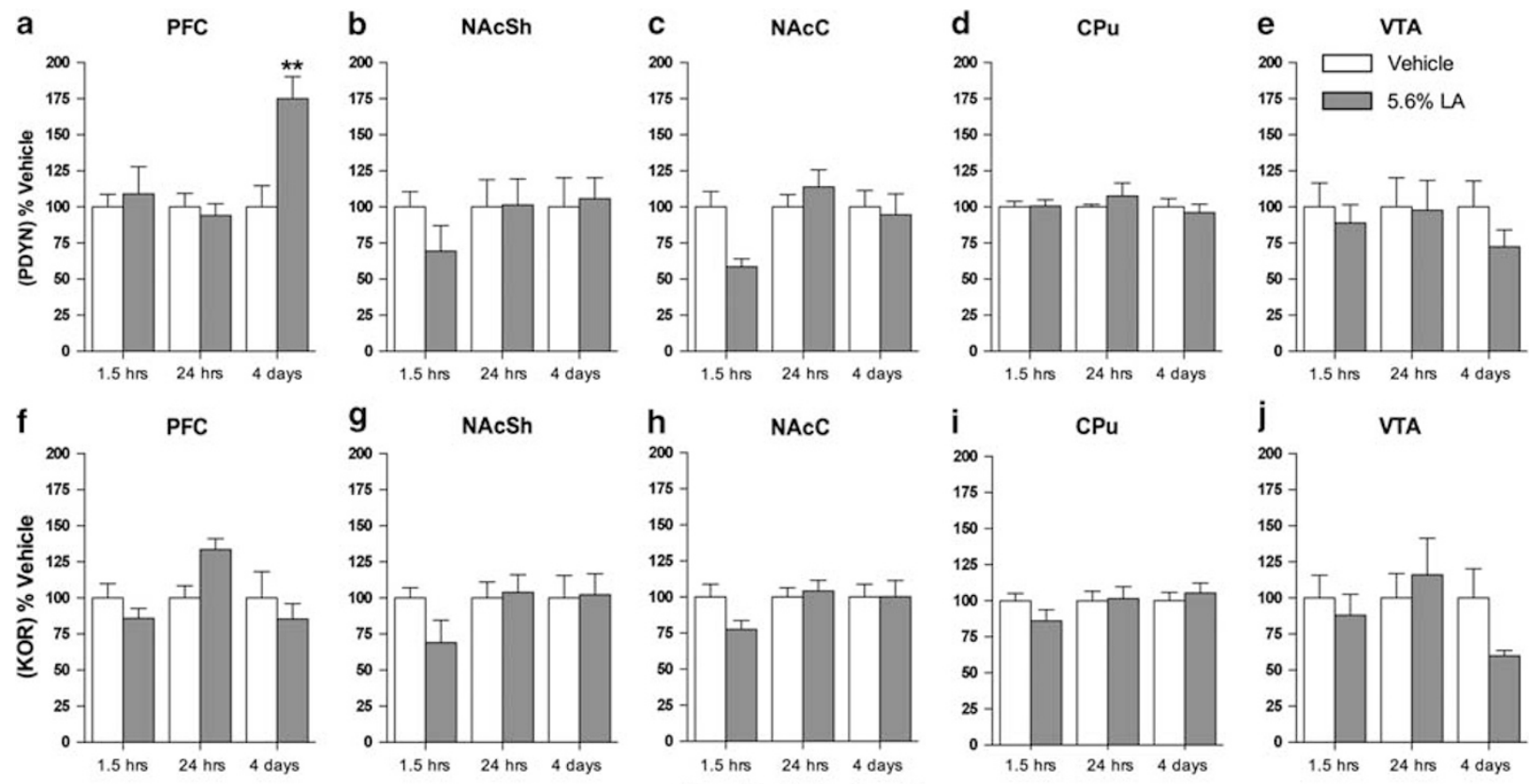

Figure 5 Pain-related modulation of PDYN and KOR mRNA expression levels in brain regions implicated in mood disorders as measured by qRT-PCR. Transcript levels of mRNA for (a-e) PDYN or ( $\mathrm{f}-\mathrm{j}) \mathrm{KOR}$ in various components of midbrain dopamine systems. The abscissae show time after acid administration and the ordinates show transcript levels expressed as percent of vehicle control. Data were analyzed by two-way ANOVA followed by the Bonferroni post hoc test. Asterisks indicate significant between-group differences within brain regions (*** $<0.0 \mathrm{I}$ ). All bars show mean \pm SEM from 6 rats. PFC, prefrontal cortex; NAcSh, nucleus accumbens shell; NAcC, nucleus accumbens core; CPu, caudate/putamen; VTA, ventral tegmental area; LA, lactic acid; PDYN, prodynorphin; KOR, א-opioid receptor.

(Carlezon et al, 2006; Zhang et al, 2005). Second, regarding potency, i.p. acid was more potent to depress ICSS than NAc DA levels. For example, we have reported previously that a concentration of $1.8 \%$ lactic acid was sufficient to significantly depress ICSS (Pereira Do Carmo et al, 2009). Although this concentration of acid reduced mean NAc DA levels in preliminary experiments for this study, the reduction was not statistically significant (mean \pm SEM \% baseline DA $=95.64 \pm 3.87$ after vehicle and $88.15 \pm 3.8$ after $1.8 \%$ acid; $p=0.21$ by $t$-test), and hence a higher intensity stimulus of $5.6 \%$ acid was tested that did significantly decrease both ICSS and NAc DA. The $\kappa$-agonists also tend to be less potent to depress microdialysis measures of NAc DA than ICSS and other behavioral end points (Carlezon et al, 2006; Negus et al, 2010b; Zhang et al, 2005). Moreover, the slower onset, longer duration, and lower potency of these treatments to depress NAc DA levels $v s$ behavior is mirrored by a similar slower onset, longer duration, and lower potency of amphetamine-like drugs to stimulate NAc DA vs behavior (eg, amphetamine; see Bauer et al, 2013; Schad et al, 1995). Taken together, these results suggest that microdialysis measures of NAc DA are slightly less sensitive to, and slower to recover from, experimental manipulations than ICSS or other behavioral measures. This difference may involve the lag between treatment-induced changes in synaptic DA (which affect behavior) and detection by microdialysis of later changes in extrasynaptic DA levels.

This is the first study to report a pain-related and analgesic-reversible decrease in microdialysis measures of NAc DA after treatment with a noxious stimulus. However, two other recent studies reported increases in NAc DA release after antinociceptive treatments in rat models of postsurgical or cephalic pain (De Felice et al, 2013; Navratilova et al, 2013). This preclinical evidence for reciprocal effects of pain- and analgesia-related manipulations on NAc DA corresponds to clinical evidence from functional magnetic resonance imaging studies for reciprocal negative/positive signals in NAc at pain onset/offset, respectively (Becerra and Borsook, 2008). Moreover, these findings agree with other clinical evidence for a negative correlation between pain and mesolimbic DA in humans (Borsook et al, 2007; Jarcho et al, 2012; Wood, 2008).

In the present study, ketoprofen completely blocked acidinduced depression of both NAc DA and ICSS at a dose that did not alter either NAc DA or ICSS when ketoprofen was administered alone. This finding agrees with previous reports that ketoprofen blocks acid-induced depression of ICSS and supports the proposition that ketoprofen reduced sensitivity to the acid noxious stimulus (Negus et al, 2010b; Kwilasz and Negus, 2012). Morphine also blocked acidinduced depression of NAC DA and ICSS at a dose that had no significant effect on NAc DA or ICSS; however, mean DA levels were increased by morphine in this study, and previous microdialysis studies have reported that similar morphine doses produced significant increases in NAc DA (eg, see Cadoni and DiChiara, 2007). In addition, $3.2 \mathrm{mg} / \mathrm{kg}$ morphine can produce significant facilitation of ICSS depending on variables such as pretreatment time and history of opioid exposure (Altarifi and Negus, 2011). Accordingly, morphine blockade of acid effects on NAc DA and ICSS may reflect both reduced sensitivity to the noxious 
stimulus and additivity of opposing acid and morphine effects on NAc DA and ICSS.

The present finding that i.p. acid depressed NAc DA contrasts with several earlier microdialysis studies in rodents showing stimulation in NAc DA release by aversive stimuli such as foot shock, tail shock, and tail pinch (Amato et al, 2011; Kalivas and Duffy, 1995; Marinelli et al, 2005). Resolution of this discrepancy will require further research, but two issues will be highlighted here as potentially important factors. First, aversive stimuli that stimulated NAc DA have all been applied cutaneously, whereas the present study used a visceral noxious stimulus. Cutaneous stimuli originating outside the body are more easily escaped than visceral stimuli and might therefore be likely to stimulate rather than depress behavior and neurochemical systems such as the mesolimbic DA system that mediate behavioral activation. For example, a 20-min exposure to tail pinch stimulated both NAc DA levels and locomotor activity in rats (Amato et al, 2011). Second, the present study found that i.p. acid-induced depression of ICSS and NAc DA release was blocked by analgesic drugs, supporting the relationship of these effects to clinical pain. In contrast, analgesics have not been evaluated for their ability to block stimulation of NAc DA release by cutaneous aversive stimuli.

\section{Role of Endogenous Dynorphin/א-Opioid Receptor Systems}

The present results with U69593 agree with numerous previous studies in showing that $\kappa$-receptor activation is clearly sufficient to depress both ICSS and NAc DA release (Carlezon et al, 2006; Negus et al, 2010b; Todtenkopf et al, 2004; Zhang et al, 2005). However, a dose of norBNI that fully blocked these effects of U69593 failed to block i.p. acid-induced depression of ICSS and NAc DA release. Conversely, U69593 effects were not blocked by a dose of ketoprofen that did block acid effects, and morphine was also more effective to block the effects of acid than of U69593. This double dissociation suggests that the endogenous dynorphin/K-opioid receptor system is not necessary for acid-induced depression of ICSS and NAc DA.

This conclusion is also consistent with the finding that i.p. acid did not elevate PDYN in NAc or other brain regions at 1.5 or $24 \mathrm{~h}$ after acid administration, and did not alter KOR at any time. However, the present results do suggest a painrelated perturbation in $\kappa$-opioid systems, and behavioral consequences of that perturbation remain to be determined. We focused on adaptations in mesocorticolimbic PDYN and KOR expression because previous work showed that nonnoxious stressors activate the transcription factor CREB (cAMP response element-binding protein) in the NAc, and that CREB-mediated increases in dynorphin function in this region contribute to depressive-like behavioral signs including anhedonia in the ICSS test (Chartoff et al, 2009; Muschamp et al, 2011; Pliakas et al, 2001). The acid noxious stimulus did not elevate NAc PDYN expression like the stressors tested in these earlier studies, but it did significantly increase PFC PDYN expression at the delayed time point (4 days). Although this effect was significant despite the use of conservative post hoc tests and $\alpha$-levels, we acknowledge that there is a possibility of type I error whenever large numbers of comparisons are made, and future studies will follow-up these early results with a more detailed characterization of the time course of this effect, as well as analysis of genes encoding other proteins. Nevertheless, these data suggest that a visceral noxious stimulus that depresses ICSS may also trigger delayed but more sustained changes (eg, those in the PFC) that increase vulnerability to depressive-like behaviors at later time points (eg, days after the initial pain stimulus). For example, recent work shows that KOR activation in the PFC causes local reductions in DA levels and establishes conditioned place aversions (Tejeda et al, 2013), suggesting that elevated dynorphin function in this region can produce another hallmark sign of depressive illness (dysphoria). These data provide a rationale for future work in which vulnerability to depressive behavior is studied at time points far beyond the acute effects of a painful/stressful stimulus (Knoll and Carlezon, 2010). In addition, the fact that our data demonstrate that acute pain can cause adaptations within the mesocorticolimbic system opens the door to the study of other target genes and proteins that are implicated in depressive behavior but that would be expected to be minimally sensitive to KOR blockade (eg, BDNF; see Berton et al, 2006).

\section{FUNDING AND DISCLOSURE}

Mr Leitl, Ms Onvani, and Drs Cheng, and Rice declare no conflict of interest. Dr Bowers declares that his research has been funded by the NIH and the Alcohol Beverage Medical Research Foundation. During the past 3 years, he has not received any compensation from private or publicly owned firms. Dr Carlezon declares that his research has been funded by NIH. He has a US patent covering the use of $\kappa$-antagonists in the treatment of depressive disorders (Assignee: McLean Hospital). In the past 3 years, Dr Carlezon has received compensation for professional services from The American College of Neuropsychopharmacology and Concert Pharmaceuticals. Dr Banks declares that his research has been funded by NIH. During the past 3 years, he has received compensation as a collaborator with the pharmaceutical companies Abbott and Purdue for projects related to opioid pharmacology and analgesic drug development. Dr Negus declares that his research has been funded by NIH. During the past 3 years, he has received compensation as a consultant for or collaborator with Abbott Pharmaceutical Company for projects related to analgesic drug development. Research reported in this publication was supported by the National Institute on Neurological Disorders and Stroke of the National Institutes of Health under Award Numbers R01 NS070715. In addition, Mr. Leitl was supported in part by T32 DA007027. Additional funding was by the Virginia Commonwealth University AD Williams Fund, and a portion of this work was also supported by the Intramural Research Programs of the National Institute on Drug Abuse and the National Institute on Alcohol Abuse and Alcoholism.

\section{DISCLAIMER}

The content is solely the responsibility of the authors and does not necessarily represent the official views of the National Institutes of Health. 


\section{REFERENCES}

Altarifi AA, Negus SS (2011). Some determinants of morphine effects on intracranial self-stimulation in rats: dose, pretreatment time, repeated treatment, and rate dependence. Behav Pharmacol 22: 663-673.

Amato D, Natesan S, Yavich L, Kapur S, Muller CP (2011). Dynamic regulation of dopamine and serotonin responses to salient stimuli during chronic haloperidol treatment. Int $J$ Neuropsychopharmacol 14: 1327-1339.

Andrews N, Legg E, Lisak D, Issop Y, Richardson D, Harper S et al (2012). Spontaneous burrowing behaviour in the rat is reduced by peripheral nerve injury or inflammation associated pain. Eur J Pain 16: 485-495.

Bair MJ, Robinson RL, Katon W, Kroenke K (2003). Depression and pain comorbidity: a literature review. Arch Intern Med 163: 2433-2445.

Bauer CT, Banks ML, Blough BE, Negus SS (2013). Use of intracranial self-stimulation to evaluate abuse-related and abuselimiting effects of monoamine releasers in rats. $\mathrm{Br}$ J Pharmacol 168: 850-862.

Baumann MH, Char GU, De Costa BR, Rice KC, Rothman RB (1994). Gbr12909 attenuates cocaine-induced activation of mesolimbic dopamine neurons in the rat. J Pharmacol Exp Ther 271: 1216-1222.

Becerra L, Borsook D (2008). Signal valence in the nucleus accumbens to pain onset and offset. Eur J Pain 12: 866-869.

Berton O, McClung CA, Dileone RJ, Krishnan V, Renthal W, Russo SJ et al (2006). Essential role of BDNF in the mesolimbic dopamine pathway in social defeat stress. Science 311: 864-868.

Borsook D, Becerra L, Carlezon WA Jr, Shaw M, Renshaw P, Elman I et al (2007). Reward-aversion circuitry in analgesia and pain: implications for psychiatric disorders. Eur J Pain 11: 7-20.

Bray GE, Ying Z, Baillie LD, Zhai R, Mulligan SJ, Verge VM (2013). Extracellular ph and neuronal depolarization serve as dynamic switches to rapidly mobilize trka to the membrane of adult sensory neurons. J Neurosci 33: 8202-8215.

Bruchas MR, Land BB, Chavkin C (2010). The dynorphin/kappa opioid system as a modulator of stress-induced and proaddictive behaviors. Brain Res 1314: 44-55.

Bruchas MR, Yang T, Schreiber S, Defino M, Kwan SC, Li S et al (2007). Long-acting kappa opioid antagonists disrupt receptor signaling and produce noncompetitive effects by activating c-jun n-terminal kinase. J Biol Chem 282: 29803-29811.

Cadoni C, DiChiara G (2007). Differences in dopamine responsiveness of drugs of abuse in the nucleus accumbens shell and core of Lewis and Fischer 344 rats. J Neurochem 103: 487-499.

Carlezon WA Jr., Béguin C, DiNieri JA, Baumann MH, Richards MR, Todtenkopf MS et al (2006). Depressive-like effects of the kappa-opioid receptor agonist salvinorin a on behavior and neurochemistry in rats. J Pharmacol Exp Ther 316: 440-447.

Carlezon WA Jr, Chartoff EH (2007). Intracranial self-stimulation (ICSS) in rodents to study the neurobiology of motivation. Nat Protoc 2: 2987-2995.

Chartoff EH, Papadopoulou M, MacDonald ML, Parsegian A, Potter D, Konradi C et al (2009). Desipramine reduces stressactivated dynorphin expression and creb phosphorylation in NAc tissue. Mol Pharmacol 75: 704-712.

Chavkin C, James IF, Goldstein A (1982). Dynorphin is a specific endogenous ligand of the kappa opioid receptor. Science 215: 413-415.

Cleeland CS, Ryan KM (1994). Pain assessment: global use of the brief pain inventory. Ann Acad Med Singapore 23: 129-138.

Cobos EJ, Ghasemlou N, Araldi D, Segal D, Duong K, Woolf CJ (2012). Inflammation-induced decrease in voluntary wheel running in mice: a nonreflexive test for evaluating inflammatory pain and analgesia. Pain 153: 876-884.
De Felice M, Eyde N, Dodick D, Dussor GO, Ossipov MH, Fields HL et al (2013). Capturing the aversive state of cephalic pain preclinically. Ann Neurol (e-pub ahead of print, doi:10.1002/ana.23922).

Deval E, Gasull X, Noël J, Salinas M, Baron A, Diochot S et al (2013). Acid-sensing ion channels (ASICS): pharmacology and implication in pain. Pharmacol Ther 128: 549-558.

Dharmshaktu P, Tayal V, Kalra BS (2012). Efficacy of antidepressants as analgesics: a review. J Clin Pharmacol 52: 6-17.

Di Chiara G, Imperato A (1988a). Drugs abused by humans preferentially increase synaptic dopamine concentrations in the mesolimbic system of freely moving rats. Proc Natl Acad Sci USA 85: 5274-5278.

Di Chiara G, Imperato A (1988b). Opposite effects of mu and kappa opiate agonists on dopamine release in the nucleus accumbens and in the dorsal caudate of freely moving rats. J Pharmacol Exp Ther 244: 1067-1080.

Endoh T, Matsuura H, Tanaka C, Nagase H (1992). Norbinaltorphimine: a potent and selective kappa-opioid receptor antagonist with long-lasting activity in vivo. Arch Int Pharmacodyn Ther 316: 30-42.

Jarcho JM, Mayer EA, Jiang ZK, Feier NA, London ED (2012). Pain, affective symptoms, and cognitive deficits in patients with cerebral dopamine dysfunction. Pain 153: 744-754.

Kalivas PW, Duffy P (1995). Selective activation of dopamine transmission in the shell of the nucleus accumbens by stress. Brain Res 675: 325-328.

Knoll AT, Carlezon WA Jr. (2010). Dynorphin, stress, and depression. Brain Res 1314: 56-73.

Kwilasz AJ, Negus SS (2012). Dissociable effects of the cannabinoid receptor agonists \{delta\}9-tetrahydrocannabinol and CP55940 on pain-stimulated versus pain-depressed behavior in rats. J Pharmacol Exp Ther 343: 389-400.

Marinelli S, Pascucci T, Bernardi G, Puglisi-Allegra S, Mercuri NB (2005). Activation of TRPV1 in the VTA excites dopaminergic neurons and increases chemical- and noxious-induced dopamine release in the nucleus accumbens. Neuropsychopharmacology 30: 864-870.

Martin TJ, Buechler NL, Kahn W, Crews JC, Eisenach JC (2004). Effects of laparotomy on spontaneous exploratory activity and conditioned operant responding in the rat: a model for postoperative pain. Anesthesiology 101: 191-203.

McLaughlin JP, Marton-Popovici M, Chavkin C (2003). Kappa opioid receptor antagonism and prodynorphin gene disruption block stress-induced behavioral responses. J Neurosci 23: 5674-5683.

Muschamp JW, Van't Veer A, Parsegian A, Gallo MS, Chen M, Neve RL et al (2011). Activation of CREB in the nucleus accumbens shell produces anhedonia and resistance to extinction of fear in rats. J Neurosci 31: 3095-3103.

Navratilova E, Xie JY, Okun A, Qu C, Eyde N, Ci S et al (2013). Pain relief produces negative reinforcement through activation of mesolimbic reward-valuation circuitry. Proc Natl Acad Sci USA 109: 20709-20713.

Negus SS (2013). Expression and treatment of pain-related behavioral depression. Lab Animal 42: 292-300.

Negus SS, Bilsky EJ, Pereira Do Carmo G, Stevenson GW (2010a). Rationale and methods for assessment of pain-depressed behavior in preclinical assays of pain and analgesia. In: Szallasi A (ed) Methods in Molecular Biology: Analgesia. Humana Press: New York, pp 79-91.

Negus SS, Morrissey EM, Rosenberg M, Cheng K, Rice KC (2010b). Effects of kappa opioids in an assay of pain-depressed intracranial self-stimulation in rats. Psychopharmacology (Berl) 210: $149-159$.

Negus SS, O'Connell R, Morrissey E, Cheng K, Rice KC (2012). Effects of peripherally restricted kappa opioid receptor agonists on pain-related stimulation and depression of behavior in rats. J Pharmacol Exp Ther 340: 501-509. 
Olds J, Milner P (1954). Positive reinforcement produced by electrical stimulation of septal area and other regions of rat brain. J Comp Physiol Psychol 47: 419-427.

Pereira Do Carmo G, Stevenson GW, Carlezon WA, Negus SS (2009). Effects of pain- and analgesia-related manipulations on intracranial self-stimulation in rats: further studies on paindepressed behavior. Pain 144: 170-177.

Pliakas AM, Carlson RR, Neve RL, Konradi C, Nestler EJ, Carlezon WA Jr (2001). Altered responsiveness to cocaine and increased immobility in the forced swim test associated with elevated camp response element-binding protein expression in nucleus accumbens. J Neurosci 21: 7397-7403.

Schad CA, Justice JB Jr., Holtzman SG (1995). Naloxone reduces the neurochemical and behavioral effects of amphetamine but not those of cocaine. Eur J Pharmacol 275: 9-16.

Stellar JR, Stellar E (1985). The Neurobiology of Motivation and Reward. Springer-Verlag: New York.

Stevenson GW, Bilsky EJ, Negus SS (2006). Targeting painsuppressed behaviors in preclinical assays of pain and analgesia: effects of morphine on acetic acid-suppressed feeding in c57bl/6j mice. J Pain 7: 408-416.

Stevenson GW, Cormier J, Mercer H, Adams C, Dunbar C, Negus SS et al (2009). Targeting pain-depressed behaviors in preclinical assays of pain and analgesia: drug effects on acetic aciddepressed locomotor activity in ICR mice. Life Sci 85: 309-315.

Tejeda HA, Counotte DS, Oh E, Ramamoorthy S, Schultz-Kuszak KN, Bäckman CM et al (2013). Prefrontal cortical kappaopioid receptor modulation of local neurotransmission and conditioned place aversion. Neuropsychopharmacology 38: 1770-1779.

Todtenkopf MS, Marcus JF, Portoghese PS, Carlezon WA Jr. (2004). Effects of kappa-opioid receptor ligands on intracranial self-stimulation in rats. Psychopharmacology (Berl) 172: 463-470.

Wee S, Koob GF (2010). The role of the dynorphin-kappa opioid system in the reinforcing effects of drugs of abuse. Psychopharmacology (Berl) 210: 121-135.

Wise RA (2008). Dopamine and reward: the anhedonia hypothesis 30 years on. Neurotox Res 14: 169-183.

Wood PB (2008). Role of central dopamine in pain and analgesia. Expert Rev Neurother 8: 781-797.

Zhang Y, Butelman ER, Schlussman SD, Ho A, Kreek MJ (2005). Effects of the plant-derived hallucinogen salvinorin a on basal dopamine levels in the caudate putamen and in a conditioned place aversion assay in mice: agonist actions at kappa opioid receptors. Psychopharmacology (Berl) 179: 551-558.

Supplementary Information accompanies the paper on the Neuropsychopharmacology website (http://www.nature.com/npp) 